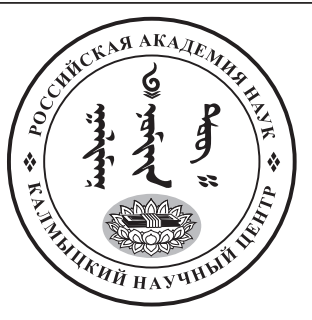

Published in the Russian Federation

Oriental Studies (Previous Name: Bulletin of the Kalmyk Institute

for Humanities of the Russian Academy of Sciences)

Has been issued as a journal since 2008

ISSN: 2619-0990; E-ISSN: 2619-1008

Vol. 13, Is. 4, pp. 941-950, 2020

DOI: $10.22162 / 2619-0990-2020-50-4-941-950$

Journal homepage: https://kigiran.elpub.ru

УДК $39(=512.31)$

DOI: $10.22162 / 2619-0990-2020-50-4-941-950$

\title{
Образ оленя-солнца и этноним бурятского племени Хори
}

\section{Надежда Базаржаповна Дашиева ${ }^{1}$}

${ }^{1}$ Восточно-Сибирский государственный институт культуры (д. 1, ул. Терешковой, 670031 УланУдэ, Российская Федерация)

доктор исторических наук, профессор

(iD) 0000-0002-3652-2535. E-mail: dashieva-n@yandex.ru

(C) КалмНЦ РАН, 2020

(C) Дашиева Н. Б., 2020

Аннотация. Введение. Статья посвящена этнониму самого многочисленного племени в составе бурятского этноса - племени Хори. Установлено, что отсутствие в этнографических исследованиях общепринятого мнения о происхождении племенного названия вызывает сложности в изучении его этногенеза и ранней этнической истории. Целью исследования является выявление языковых и историко-культурных индикаторов происхождения термина «хори» как этнонима бурятского племени Хори и выявление этимологии племенного этнонима. В качестве материала использованы тексты шаманских призываний хори-бурят, сведения монгольских письменных источников, сюжеты петроглифов северного берега Байкала. Результаты. Историко-сравнительный и историко-сопоставительный анализ материала с аналогичными фактами в культуре тюрко-монгольских народов Центральной Азии и Южной Сибири показал, что словесное описание оленя-матери в шаманских текстах хоринских родов возводит его образ к скифо-сибирской канонической традиции изображения животных на каменных плитах, сопровождающих курганные захоронения в Западной и Северо-Западной Монголии, на Алтае и в Северной Туве. Историко-культурный и языковой этнические индикаторы возводят этимологию этнонима Хори к лексеме «хор» как названия солнца и его символа — оленя у кочевых ираноязычных племен бронзового и раннего железного века степей Центральной Азии и Южной Сибири. Общее культовое отношение к лебедю - тотемной птице со стороны материнского происхождения у хори-бурят, западных монголов и телеутов в сравнительно-сопоставительном анализе определяют этно- и культурную связь этнических предков племени Хори с тюркскими племенами с культом лебедя через этническое объединение «тумат», территориально связанное с Саяно-Алтаем. Bыводы. Выявленные в исследовании сведения указывают на происхождение этнонима племени Хори в едином историко-культурном пространстве с кочевыми народами степей Центральной Азии - носителями культуры плиточных могил с культом солнца и культом оленя-предка в его женской ипостаси.

Ключевые слова: племя Хори, буряты, этноним, олень-солнце, лебедь, теле, тумат, «звериный стиль», кочевники 
Для цитирования: Дашиева Н. Б. Образ оленя-солнце и этноним бурятского племени Хори

// Oriental Studies. 2020. T. 13. № 4. C. 941-950. DOI: 10.22162/2619-0990-2020-50-4-941-950

UDC $39(=512.31)$

DOI: $10.22162 / 2619-0990-2020-50-4-941-950$

\title{
Image of the Deer-Sun and Ethnonym of the Khori Buryats
}

\author{
Nadezhda B. Dashieva ${ }^{1}$ \\ ${ }^{1}$ East Siberian State Institute of Culture (1, Tereshkova St., Ulan-Ude 670031, Russian Federation) \\ Dr. Sc. (History), Professor \\ (iD) 0000-0002-3652-2535. E-mail: dashieva-n@yandex.ru
}

(C) KalmSC RAS, 2020
(C) Dashieva N. B., 2020

\begin{abstract}
Introduction. The article examines the ethnonym of the largest Buryat tribe - Khori. The absence of universally accepted etymology thereof in Buryat ethnography significantly complicates ethnogenetic studies dealing with earliest ethnic history. Goals. The work seeks to reveal linguistic, historical, and cultural etymology-related properties of the term 'Khori' in Buryat ethnonymic discourse. Materials and Methods. The article analyzes texts of Khori Buryat shamanic invocations, data from Mongolian written sources, and petroglyphs from the northern shore of Lake Baikal. The materials have been studied using the methods of historical comparative, historical contrastivecomparative, cultural semantic and linguistic analyses, reference data being similar facts from cultures of Turko-Mongols inhabiting Central Asia and Southern Siberia. Results. The image of the Mother Deer described in shamanic texts of Khori clans settled in the mouth of the Selenga River can be traced to the Scytho-Siberian canonical tradition of depicting animals on stone slabs that accompany burial mounds containing Caucasoid remains in the mountainous regions of Western and Northwestern Mongolia, similar to Pazyryk mounds of the Altai and Uyuk mounds of Northern Tuva. Historical, cultural and linguistic ethnic indicators allow for the possibility the ethnonym 'Khori' may derive from the word 'khor' used to denote the Sun and its symbol - Deer - among the Bronze and Early Iron Age nomadic Iranian-speaking tribes of Central Asia and Southern Siberia. A comparative insight into common traditions of worshipping the Swan - maternal totem bird of the Khori Buryats, Western Mongols, and Teleuts - makes it possible to determine ethnic and cultural ties between ethnic ancestors of the Khori and Turkic tribes with the Swan cult through the ethnic union referred to as 'Toumat' and geographically connected with the Sayan-Altai. The research shows that the origins of the ethnonym 'Khori' is closely related to the history and culture of Central Asian nomads representatives of the stone grave culture characterized by the solar cult and that of the Mother Deer. Keywords: Khori tribe, Buryats, ethnonym, swan, sun deer, Tele, Toumat, animal style, nomads For citation: Dashieva N. B. Image of the Deer-Sun and Ethnonym of the Khori Buryats. Oriental Studies. 2020. Vol. 13(4): 941-950. (In Russ.). DOI: 10.22162/2619-0990-2020-50-4-941-950
\end{abstract}

\section{है}

\section{Введение}

В этнографии бурят до настоящего времени отсутствует общепринятое мнение о происхождении названия самого многочисленного в его составе племени - субэтнической группы Хори. Данное обстоятельство способствует сохранению дискуссионности в вопросах его этногенеза и ранней этнической истории. Так, Б. Р. Зориктуев, посвятивший специальную статью анализу публикаций по проблеме этногенеза племени Хори, приходит к выводу, что с ростом их числа расширился и разброс противоречащих друг другу мнений [Зориктуев 2019: 18]. 
Целью исследования является выявление языковых и историко-культурных индикаторов происхождения слова «хори» как этнонима бурятского племени Хори и выявление этимологии этого этнонима. При постановке цели мы руководствуемся методическими указаниями известного историка-востоковеда, лингвиста И. М. Дьяконова о необходимости в исследованиях по этнической истории, прежде всего, установления того, являлось ли название народа самоназванием или же это было названием, применявшимся только соседями (иноназванием) [Дьяконов 1981: 90].

И. М. Дьяконов писал: «... если мы сможем установить, что некоторый этноним являлся самоназванием и определим ареал его употребления, то мы тем самым выделим некий исторический социум»; «Имея достоверное самоназвание и представление об ареале его распространения, мы можем получить дополнительные сведения, установив обстоятельства возникновения самоназвания и его перехода с части племени на целое или даже с одного племени на другое. При этом значительную дополнительную информацию может дать лингвистика через сравнительно-исторический анализ тех форм, в которых данное самоназвание-этноним засвидетельствован в письменных источниках» [Дьяконов 1981: 92].

\section{История вопроса}

В ряде публикаций, посвященных проблеме этногенеза и этнической истории племени Хори, его этноним возводится к предполагаемому самоназванию монголоязычных сяньбийцев как $\partial y н-x y$, появление которых на исторической арене относится к I в. н. э. Так, Г. Н. Румянцев, указав, что корень хор лежит в основе многих названий монгольских племен, хорами называют монголов тибетцы, допускает вероятность того, что «хор - мн. (множественное. - Н. Д.) число от хо или $x y$. Тогда китайское наименование предков сяньбийцев - дун-ху „северные варвары“, может быть истолковано и как „,северные хоры“» [Румянцев 1962: 127]. Правомерность такого положения автор обосновывает мнением синолога В. П. Васильева, который в 1890 г. на основе того, что тибетцы монголов называли $x о p$, полагал, что оно могло быть общим наименованием большой группы древних протомонгольских племен, расселенных на большом пространстве от Прибайкалья до Восточной Монголии.

К названию хор данный исследователь возводит этноним средневекового населения Прибайкалья VI-X вв. - курыкан, культура которых генетически связана с предшествующей ей культурой «плиточных могил» бронзового и раннего железного века Прибайкалья и Забайкалья [Румянцев 1962: 128].

Филолог и историк-монголовед Ц. Б. Цыдендамбаев, поддерживая взгляды Г. Н. Румянцева о связи племенного этнонима с предполагаемым самоназванием сяньбийцев как $\partial y н-x y-$ «северные хоры», считает «не лишенной основания гипотезу об отпочковании хоринцев от какой-то части хоров-сяньбийцев после распадения их единства» [Цыдендамбаев 2001: 164].

К названию $у y н-x y$, признавая их общими предками всех монголоязычных народов, возводит этноним хори и Б. Б. Дашибалов. Исходя из близости его звучания с этно- и топообразующим корнем хор со значением «солнце» в Иране, Средней Азии и Европе, исследователь предполагает, «что этноним $x y$ или хор связан с древним индоиранским распространением и в дальнейшем стал самоназванием древних монголов» [Дашибалов 2005: 46-47].

Б. Р. Зориктуев со ссылкой на свои экспедиционные материалы, полученные в Тибете, свидетельствует, что хор у тибетцев является общим наименованием всех кочевых скотоводов независимо от их этнической принадлежности, а не только монголов [Зориктуев 2011: 25; Зориктуев 2019: 128].

Б. 3. Нанзатов происхождение племени хори связывает со средневековым тюрко-

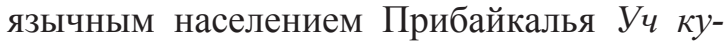
рыкан ('Три курыкана'), название которого возводит к древнетюркской лексеме gurigan со значением «стан, военный лагерь». Полагая, что хоринцы составляли один из трех лагерей, праформой его этнонима видит тюркские слова gori - goru, посредством которых передаются понятия «оберегать, охранять» [Нанзатов 2005: 18, 20; Нанзатов 2010: 343-344].

Каждое из приведенных мнений обнаруживает контекстную связь с отдельными вопросами, рассмотренными в трудах известного российского востоковеда, тибетолога 
и монголиста, специалиста по тибетским письменным источникам и языку Ю. Н. Рериха, посвященных истории и культуре кочевых народов Тибета. Согласно изысканиям Ю. Н. Рериха, слово хор как название кочевых народов в его историческом и современном применении у тибетцев имеет разные значения. Исторически данным словом называли племена тюрко-монгольского происхождения [Рерих 1999а: 42], а в современном тибетском разговорном языке оно передает понятие «кочевник смешанного происхождения» независимо от их собственных родовых названий [Рерих 1999б: 89].

Историческую основу культурного единства хоров Тибета исследователь видит в элементах искусства «звериного стиля», ареал распространения которого ограничивается его северными областями и связывается с плиточными могилами, известными в области Нуп-Хор ('Западный Хор'). Население этой области хор-na ('хоры'), широко использующее предметы быта с орнаментом «звериного стиля», исторически относилось к центрально-азиатским племенам иранского и тюрко-монгольских корней [Рерих 1999а: 40, 41; Рерих 1999б: 93].

В контексте «звериного стиля» как признака культурного единства кочевых племен Тибета с общим названием хор рассмотрим возможность его проявления в этнониме бурятского племени Хори.

\section{Хори-буряты и искусство «звериного стиля»}

Непосредственная связь хори-бурят с населением плиточных могил и с искусством «звериного стиля» представлена в текстах шаманских призываний родов-переселенцев с северного берега Байкала и оз. Ольхон в устье Селенги. В этих текстах в паре божественных первопредков племени выступают орел-отец с «собственным именем» Хан-Хута-баабай (дух-хозяин оз. Ольхон) и богиня-прародительница с «собственным именем» Шомшор Большая госпожа, с «прозвищем» Уhэтэ Госпожа-мать [Жамцарано 2001: 161].

Сочетание в образной характеристике богини-прародительницы бурятских слов шомшор (со значением 'вытянутые губы') и yhэmэ ('волосатая / длинноволосая') указывает на стилизованные фигуры оленей с длинными, вытянутыми наподобие птичьего клюва мордами и запрокинутыми на спину развесистыми рогами, концы которых туго закручивались. Такие олени изображены в позе летящего галопа на каменных плитах, известных в археологии как «оленные камни». Исторически «оленные камни» так же, как и культ оленя, и «звериный стиль», связаны с кочевыми скотоводческими племенами Западной и Северо-Западной Монголии, Тувы и Алтая эпохи ранней бронзы [Новгородова 1989: 173-174].

В шаманском призывании хори-бурят «собственное имя» богини вкупе со значением ее «прозвища» семантически перекликается с клишированным выражением «с гребневидными волосами» в характеристике богини-прародительницы огненной природы Умай / Майлган / Маі-ана в обрядово-ритуальных текстах тюрко-монгольских народов Центральной Азии и Южной Сибири [Каруновская 1927: 27-28; Сагалаев 1990: 23-24].

Генеалогический миф племени хори, существующий в нескольких вариантах, его истоки возводит к женитьбе молодого охотника Хоридой-мэргэна на небесной деве-лебеди, которую он видит в образе прекрасной девушки, купающейся в озере. Юноша крадет лебединые одежды красавицы, и она становится его супругой. Дева-лебедь, прожив с Хоридоем много лет, родив ему одиннадцать сыновей, в старости вновь преображается в свой птичий облик и улетает в небесный мир, наказав потомкам весной и осенью, встречая и провожая лебедей, брызгать им вслед молоком.

В различных вариантах мифа местом встречи прародителей племени указываются разные территории. Это легендарное для хоринцев озеро Садамтын Саган, находящееся где-то в далекой стране; имеется сюжет, в котором под названием Садамтын нур выступают три небольших озера на р. Лене. В наиболее распространенных вариантах мифа встреча отца-основателя племени с девой-лебедицей происходит на северном берегу Байкала, или на острове Ольхон.

Иллюстрацию к байкальскому варианту сюжета мифа можно видеть в петроглифах бухты Ая и Саган-Заба ('Белая Скала'), представленных в книге А. П. Окладникова «Петроглифы Байкала - памятники древней культуры народов Сибири» [Окладни- 
ков 1974: 10-31; 32-39]. Автор, выделив среди петроглифов бухты Саган-Заба изображения оленей в позе с подогнутыми ногами и широко раскинутыми на голове рогами, видит в них сходство с оленями на бронзе тагарской культуры и «отчасти» с фигурами благородных оленей на оленных камнях Забайкалья. Эти рисунки датируются половиной I тыс. до н. э. [Окладников 1974: 77].

В группе рисунков с оленями, выполненных в канонической скифо-сибирской традиции, находятся семь фигур птиц, похожих на гусей или лебедей, расположенных вертикально одна над другой [Окладников 1974: 29; 136, 137 (табл. 11, 12)]. В изображениях лебедей А. П. Окладников обнаруживает «перекличку» с образом лебедя в мифе хоринцев о Хоридой или Хоридой-мэргэне, сочетавшемся браком на берегу Байкала с небесной девой-лебедем [Окладников 1974: 88-91].

Название лебедя у бурят хун-шубуун ('солнечная птица') происходит от тюркской лексемы кун со значением «солнце». В вариантах мифа к тюркскому названию лебедя куба восходит имя жены Хоредоя Хобоши-хатун [Румянцев 1962: 150].

Тема «солнечная птица лебедь мать-прародительница хоринских родов», рассмотренная в публикациях [Галданова 1992; Дугаров 1993; Цыдендамбаев 2001], получила логическое развитие в работах Б. Р. Зориктуева. Ученый, используя метод сравнительно-сопоставительного анализа сюжетов генеалогических мифов бурятских племен хори, хонгодор и рода шошолок с аналогичными сюжетами ряда тюркских племен, приходит к выводу о формировании тотемного культа лебедя - дочери солнечного божества, в связи с территорией Алтая, телескими племенными объединениями начала н. э. [Зориктуев 2018; Зориктуев 2019]. Согласно выводам исследователя озеро Садамтын Саган, где по одному из сюжетов хоринского мифа происходит встреча отца-основателя племени Хоредой-мэргэна с праматерью девой-лебедицей, - это местность Цайдам, расположенная между Монголией и Тибетом. Здесь происходил процесс этногенеза и ранней этнической истории племени Хори [Зориктуев 2019: 131; Зориктуев 2020].
В шаманском пантеоне кудинских бурят Предбайкалья Хоредой и его жена Хобожи-Монгон почитаются как добрые «сайтинские боги» (сайтани бурхад). К ним относили и духов-хозяев водных глубин с общим названием «Цари вод» (Уhaн-xam). К сайтинским богам, живущим в великолепных сияющих дворцах у озера Садамтын Саган, приходят после смерти белые шаманы [Хангалов 1958: 391].

По нашему мнению, сайтани как общее название категории светлых, добродетельных для людей небесных богов, восходит к лексеме ксай, присутствующей в именах героев скифской мифологии. Согласно скифскому мифу, во времена их первого царя Таргитая, по своему имени и функциям связанного с образами индоевропейских богов-громовников, атрибутом которых являлся топор или молот, с неба упали пылавшие огнем три золотых предмета. Все они достались младшему из трех сыновей. Их имена Рипоксай, Липоксай и Колоксай, в первой части означающие соответственно «гора», «глубь» и «солнце», вкупе с присутствующими во второй части иранским элементом ксай со значением «царь, владыка», выступают как коды трехчастной по вертикали индоевропейской картины мира [Раевский 1992: 446, 447].

Фонетический вариант элемента ксай в форме хшайта - эпитета первых царей иранской мифологии - означал такие понятия, как «сияющий», «властвующий». Носителем его был и сын солнечного героя и сам подобный солнцу Йима, создавший по велению и с помощью Ахурамазды прекрасную благую обитель у горы Высокой Хары (Хара Березайти) и моря Воурукуша [Бонгард-Левин, Грантовский 1983: 64]. Архетипом представлений кудинских бурят-шаманистов о месте нахождения светлых сайтинских божеств Хоредоя и его супруги-лебедицы, вероятно, явилось описание этой чудесной обители.

Параллели образам героев скифской мифологии в шаманизме бурят северного берега Байкала можно видеть в молитвенной просьбе, обращенной к духу-хозяину бухты Саган-Заба «спуститься молнией», стать бурханом с престолом между гор. В этих текстах мать-прародительница называется Буга-хатан ('Олень-царица'), а мужское божество выступает под табуированным 
именем «Бурхан, имеющий изображение среди скал, Старец Буурал» [Окладников 1974: 19].

Образ божества с функциями бога-громовника, спускающегося молнией, соотносим с одной из фигур на петроглифах бухты Саган-Заба. Это «Крупная антропоморфная фигура с рожками-развилками на голове и каким-то предметом, изображенным в виде поперечного стержня в опущенных вниз вдоль тела руках». Относительно значения этого предмета А. П. Окладников сообщает, что на табл. Н. Н. Агапитова, выполненной летом 1881 г., на конце стержня показана поперечная полоска, напоминающая боевой топор, секиру или молот [Окладников 1974: $11,25,26,72,132$ (табл. 7)].

Изображения боевых топоров, находящиеся среди набора оружия на оленных камнях, стоящих около плиточных могил в Забайкалье, датируются VII-V вв. до н. э. временем расцвета местной бронзовой культуры [Окладников 1976: 347, 352]. Аналогии им находятся в культурах скифского времени на территории Западной Монголии, Тувы и Алтая [Новгородова 1989: 263].

В искусстве кочевников бронзового века графическим символом солнца выступают свастические знаки, сопряженные с образом оленя. Преемственность с данной традицией можно видеть в мифах «старших» родов хоринского племени Шарат и Хангин, проживавших в Приангарье. В их сюжетах отцом девы-лебедицы называется Шара-Хасар-тэнгэри [Хангалов 1958: 405-406], имя которого в прямом переводе с бурятского языка осмысливается как «Желтая-Щека-тэнгэри» [Хангалов 1958: прим. ред. 2].

На наш взгляд, часть «Хасар» в структуре теонима может являться стяжением двух слов, каждое из которых лексически и семантически связано с образом солнца. У бурят графический символ солнца в виде свастического знака обозначается лексемой $x a c$ (хас тамzа), а от корня ap/aаp в тюрко-монгольских языках образуются термины культовой лексики, передающие понятия «сакральная чистота», «светлый», «священный», «великий». Так, имя высшего божества якутского пантеона - Үрун Аар-тойон ('Белый Великий-господин'), он - персонификация солнца как источника жизни на земле, а его супруга носит имя Хубай-хатун ('Лебедь-госпожа'). Лексиче- ски и семантически имя якутского божества имеет близость с арья - эпитетом богов в ведах [Сидоров 1997: 121-122].

В свете приведенного теоним небесного покровителя «старших» хоринских родов можно интерпретировать как «Тэнгри-Солнечного-Света», само солнце.

Кроме хори-бурят, традиция возведения своей родословной к лебедю как родовому тотему со стороны материнского происхождения распространена у монголов. Родословную олетских князей ведут от дочери Неба Хан Хормуста-тэнгри, представляя ее в образе лебедя. Лебедя считали своей праматерью баяты района Убса-нура [Эрдэнэболд 2012: 9, 73].

У некоторых родов баргутов невестка, впервые входя в дом, совершала обряд поклонения лебедю [Галзут 2008: 112]. Параллели культовому отношению к лебедю как тотему со стороны материнского рода у хоринцев, баятов, олетов и баргутов представлены в свадебных традициях телеутов. $\mathrm{У}$ телеутов мужчина преподносил в подарок убитого лебедя дяде по линии матери, если сватал его дочь [Потапов 1959: 20-22].

В исторической ретроспективе обычаи монгольских этнических групп были обусловлены традицией заключения браков с девушками из тюркского по происхождению материнского рода, с тотемным культом лебедя. В контексте древнего обычая, пережитки которого сохранялись у телеутов, важно привести сообщение Д. А. Функа, что большая часть саяно-алтайских тюрков знает эту этническую общность под именем байат / паячат, а их легендарная родина связана с почитанием небесного божества Тумат-тенере [Функ 1997: 4, 45-47]. В шаманских текстах телеутов дух-покровитель реки Малый Бачат назывался «С девичьим ликом Куба-Кадын, уважаемый!» [Функ 1997: 56-57].

Территориальная связь между этническим «тумат» и этническим «телеут», позволяет рассматривать этно- и культурную общность этнических предков бурятского племени хори с телескими племенами с культом лебедя - тотема материнского рода через туматов.

Впервые в письменных источниках название бурятского племени хори засвидетельствовано в «Сокровенном сказании монголов», датируемом 1240 г.: Пара- 
граф 8. Баргучжин-гоа, дочь Бархудай-Мергана, владетеля Кол-баргучжин-догумского, была выдана замуж за Хорилартай-Мергана, нойона Хори-Туматского. Алан-гоа, их дочь, была рождена у Хорилартай-Мергана от Баргучжин-гоа в Хори-Туматской земле, в местности Арих-усун. Параграф 9. По той причине, что на родине, в Хори-Туматской земле, шли взаимные пререкания и ссоры из-за пользования звероловными угодьями, Хорилартай-Мерган решил выделиться в отдельный род - обок, под названием Хорилар [Сокровенное сказание 1990: 12-13].

В монгольском источнике термин «хори» выступает в нескольких значениях, являясь: 1) основой личного имени вождя в форме Хорилартай; 2) частью названия самостоятельной политической единицы Хори-Туматской земли; 3) названием самостоятельного отцовского рода Хорилар.

Сочетание «Хори-Туматская земля» и «нойон (владетель) Хори-Туматский» могло произойти лишь при условии, если хоринцы и туматы проживали на смежных территориях. У Рашид-ад-дина читаем: «кори, баргу, тумат и байаут», ... «из коих некоторые суть монголы» и обитают в местности Баргуджин-Токум» ... [Рашид-ад-дин 1952: 121], расположенной у Байкала. Вместе с тем источник сообщает о более раннем месте расселения туматов в верховьях Енисея, известного как Секиз-мурэн (Восьмиречье), «в древности по течению этих рек сидело племя тумат» [Рашид-ад-дин 1952: 118].

В сочетании Хори-Тумат хоринцы выступают как часть туматов, и, лишь выделившись из этого союза в отдельный отцовский род, становятся носителями этнонима «хори». В форме этнического названия Хорилар часть «лар» является окончанием множественного числа в тюркских языках. Что касается части «тай» в имени Хорилартай, то согласно указанию Рашид-ад-дина у монгольских народов в начале II-го тыс. н. э. суффикс «тай» выступал показателем принадлежности к роду по мужской линии [Рашид-ад-дин 1952: 77]. Между тем в прошлом у бурят оно означало родовое божество, связанное с представлениями о женщине-прародительнице [Балдаев 1959: 9].

Предположительно, у алтайских тюрков первоначально термин «тай» относился ко всем родственникам по линии матери, лишь впоследствии им стали обозначать брата матери как представителя материнской семьи [Дыренкова 1937: 20-21]. В этимологическом словаре тюркских языков центральным значением термина является «дядя по материнской линии». Исходя из этого Э. В. Севортян допускает, что «компонент тай-дай во всех сочетаниях и сращениях ... по логике функционирует, вероятно, в значении „мать“» [Севортян 1974: 128].

В свете положения, согласно которому в древнем обществе тотем сопутствовал материнскому роду, а название тотема становилось названием рода, - структурообразующим центром социальной общины с этнонимом «хори», заключавшей браки с тюркскими родами с культом лебедя со стороны материнской линии происхождения, выступала тотемическая группа с культом оленя-солнца с иранским названием «хор».

Кем же были этнические предки большого круга тюрко-монгольских племен с тотемным культом лебедя и оленя?

На высоком головном уборе молодой женщины из захоронения с плато Укок на Алтае прикреплены пятнадцать деревянных фигурок лебедей и двух оленей, один из которых изображен стоящим на шаре. На запястье женщины, принадлежащей к европеоидному компоненту в пазырыкской культуре, изображена голова оленя с большими рогами [Полосьмак 1999: 36-41].

Семантическую функцию войлочных фигурок лебедей, набитых оленьей шерстью, найденных при раскопках Пятого Пазырыкского кургана среди деталей погребальной повозки, П. П. Азбелев объясняет воззрениями об их способности проникать в разные миры [Азбелев 2019]. В традиционной культуре хори-бурят и монголов эти воззрения выражались в ритуале кропления женщинами молоком при встрече прилетающих весной лебедей. В то же время у ойрат-монголов существовал строгий запрет даже провожать взглядом улетающих осенью водоплавающих птиц, считалось, что вместе с ними человека может покинуть благополучие. По поверьям ойрат-монголов и тюрков Южной Сибири, осенью птицы улетали в «иной», «верхний» мир.

Семантика оленьей шерсти проявляется в обычае западных монголов. Так, у захчинов в семьях, где держали коров, хранили шерсть оленя [Эрдэнэболд 2012: 72]. 
В глубокой исторической ретроспективе эти представления выражали отношение к оленю как символу солнца - источнику, дарующему жизнь и плодородие.

\section{Заключение}

Историко-культурный и языковой этнические индикаторы возводят этимологию этнонима бурятского племени хори к лексеме «хор» — названию солнца и его символа

\section{Литература}

Азбелев 2019 - Азбелев П. П. Пазырыкские лебеди // Актуальные вопросы истории кыргызского народа: прошлое, настоящее и будущее: Сб. статей в честь 70-летия кыргызского историка и востоковеда А. М. Мокеева / редкол.: К. Белек, Н. Абдимиталип уулу. Бишкек: Издат дом. «Global Print», 2019. C. $277-284$.

Балдаев 1959 - Балдаев С. П. Бурятские свадебные обряды. Улан-Удэ: Бурят. кн. изд-во, 1959. $180 \mathrm{c}$.

Бонгард-Левин, Грантовский 1983 - Бонгард-Левин Г. М., Грантовский Э. А. От Скифии до Индии. Древние арии: мифы и история. 2-е изд., доп. и испр. М.: Мысль, 1983. 206 с., ил.

Галданова 1992 - Галданова Г. Р. Закаменские буряты. Историко-этнографические очерки (вторая половина XIX - первая половина ХХ в.). Новосибирск: Наука. 1992. 172 с.

Галзут 2008 - Галзут Тубшинима. История происхождения баргутов (транслитерация, перевод, примечания) / ввод. ст. и прим. Д. Д. Нимаева, Л. Б. Бадмаевой; транслит., пер. со старомонг. Л. Б. Бадмаевой, Ю. Д. Бадмаевой. Улан-Удэ: Изд-во БНЦ CO PAH, 2008. 188 c.

Дашибалов 2005 - Дашибалов Б. Б. На монголо-тюркском пограничье (Этнокультурные процессы в Юго-Восточной Сибири в средние века). Улан-Удэ: Изд-во БНЦ СО РАН, 2005. $202 \mathrm{c}$.

Дугаров 1993 - Дугаров Д. С. К проблеме происхождения хонгодоров // Этническая история народов Южной Сибири и Центральной Азии / отв. ред. Б. Р. Зориктуев. Новосибирск: Наука. 1993. С. 207-235.

Дыренкова 1937 - Дыренкова Н. П. Пережитки материнского рода у алтайских тюрков // Советская этнография. 1937. № 4. С. 18-45.

Дьяконов 1981 - Дьяконов И. М. К методике исследований по этнической истории («ким-
- оленя у кочевых ираноязычных племен бронзового и раннего железного века степей Центральной Азии.

Ирано-тюркское «хоролар» - собирательное название групп с культом оленя-солнца - в тюрко-монгольской среде персонифицировалось в имя мифического прародителя отцовского рода Хорилартай, в бурятской мифологии перешедшее в форму Хоридой/Хоридай.

мерийцы») // Этнические проблемы истории Центральной Азии в древности (II тысячелетие до н. э.) / редкол.: М. С. Асимов и др. М.: Наука, 1981. С. 90-100.

Жамцарано 2001 - Жамиарано Ц. Путевые дневники 1903-1907 гг. / сост.: В. Ц. Лыксокова, Ц. П. Ванчикова, И. В. Кульганек. Улан-Удэ: Респ. тип., 2001. 380 с.

Зориктуев 2011 - Зориктуев Б. Р. Актуальные проблемы этнической истории монголов и бурят. М.: Вост. лит., 2011. 278 с.

Зориктуев 2019 - Зориктуев Б. Р. К истории племенной группы хори // Вестник Калмыцкого университета. 2019. № 3 (43). С. 13-19.

Зориктуев 2018 - Зориктуев Б. Р. О малоизвестных аспектах этнической истории хори // Проблемы социально-экономического развития Сибири: научный журнал. 2018. № 4(34). C. 127-132.

Зориктуев 2020 - Зориктуев Б. Р. Наян-Нава и проблема этногенеза бурятской племенной общности хори // Научный диалог. 2020. № 5. C. 393-423. DOI: $10.24224 / 2227-1295-$ 2020-5-393-423

Каруновская 1927 - Каруновская Л. Э. Из алтайских верований и обрядов, связанных с ребенком // Сборник Музея антропологии и этнографии. Т. 6. Л.: Изд-во АН СССР, 1927. C. 19-36.

Нанзатов 2005 - Нанзатов Б. З. Этногенез западных бурят (VI-XIX вв.) Иркутск: ЗАО Рекламно-полиграф. центр «Радиан», 2005. $155 \mathrm{c}$.

Нанзатов 2010 - Нанзатов Б. 3. Тюркский пласт бурятской этнонимии эпохи господства тюркских каганатов // Этногенез и культурогенез в Байкальском регионе (средневековье) / отв. ред. серии П. Б. Коновалов. Улан-Удэ: Изд-во БНЦ СО РАН, 2010. С. $330-350$.

Новгородова 1989 - Новгородова Э. А. Древняя Монголия (Некоторые проблемы хронологии и этнокультурной истории). М.: Наука, 1989. 382 c. 
Окладников 1974 - Окладников А. П. Петроглифы Байкала - памятники древней культуры народов Сибири. Новосибирск: Наука, 1974. 161 с.: табл.

Окладников 1976 - Окладников А. П. Оленный камень с реки Иволги // А. П. Окладников. История и культура Бурятии. Улан-Удэ: Бурятское кн. изд-во, 1976. С. 343-360.

Полосьмак 1999 - Полосьмак Н. В. Алтайская леди: Удивительная находка российских археологов // Родина. 1999. № 4. С. 34-41.

Потапов 1959 - Потапов Л. П. Из истории ранних форм семьи и религиозных представлений (обычай дарения лебедя у хакасов) // Советская этнография. 1959. № 2. С. 18-30.

Раевский 1992 - Раевский Д. С. Скифо-сарматская мифология // Мифы народов мира. Т. 2 / гл. ред. С. А. Токарев. М.: Российская энциклопедия, 1992. С. 445-450.

Рашид-ад-дин 1952 - Рашид-ад-дин. Сборник летописей / пер. Л. А. Хетагурова. Т. 1. Кн. 1. М.; Л.: Изд-во АН СССР, 1952. 212 с.

Рерих 1999а - Рерих Ю. Н. Звериный стиль у кочевников Тибета // Рерих Ю. Н. Тибет и Центральная Азия: статьи, лекции, переводы. Самара: Издат. дом «Агни», 1999. С. 29 50.

Рерих 19996 - Рерих Ю. Н Кочевые племена Тибета // Рерих Ю. Н. Тибет и Центральная Азия: статьи, лекции, переводы. Самара: Издат. дом «Агни», 1999. С. 88-94.

Румянцев 1962 - Румянцев Г. Н. Происхождение хоринских бурят. Улан-Удэ: Бурят. кн. изд-во, 1962. 265 с.

\section{References}

Azbelev P. P. Pazyryk swans. In: Kairat Belek, Nursultan Abdimitalip uulu (eds.) The Actual Problems of Kyrgyz History: Past, Present and Future. Collection of Articles Dedicated to the $70^{\text {th }}$ Birth Anniversary of Orientalist and Historian Prof. A. Mokeev. Bishkek: Global Print, 2019. Pp. 277-284. (In Russ.)

Baldaev S. P. Buryat Wedding Rites. Ulan-Ude: Buryat Book Publ., 1959. 180 p. (In Russ.)

Bongard-Levin G. M., Grantovsky E. A. From Scythia to India. Aryan Peoples: Myths and History. $2^{\text {nd }}$ ed., rev. and suppl. Moscow: Mysl, 1983. 206 p. (In Russ.)

Dashibalov B. B. Turko-Mongolian Frontier: Ethnocultural Processes in Medieval Southeastern Siberia. Ulan-Ude: Buryat Scientific Center (Siberian Branch of RAS), 2005. 202 p. (In Russ.)
Сагалаев 1990 - Сагалаев А. М. Птица, дающая жизнь (из тюрко-угорских мифологических параллелей) // Мировоззрение финно-угорских народов: сб. науч. тр. / отв. ред. И. Н. Гемуев. Новосибирск: Наука, СО, 1990. С. 21-34.

Севортян 1974 - Севортян Э. В. Этимологический словарь тюркских языков. Т. 1. Общетюркские и межтюркские основы на гласные. М.: Наука, 1974. 768 с.

Сидоров 1997 - Сидоров Е. С. Якутские лексические схождения. Якутск: Изд-во ЯГУ, 1997. Вып. 1. 146 с.

Сокровенное сказание 1990 - Сокровенное сказание монголов / пер. С. А. Козина. Улан-Удэ: Бур. кн. изд-во, 1990. 147 с.

Функ 1997 - Функ Д. А. Телеутское шаманство: традиционные этнографические интерпретации и новые исследовательские возможности. М.: ИЭА РАН, 1997. 268 с.

Хангалов 1958 - Хангалов М. Н. Собрание сочинений. Т. 1. Улан-Удэ: Бурят. кн. изд-во, 1958. $551 \mathrm{c}$.

Цыдендамбаев 2001 - Цылендамбаев Ц. Б. Бурятские исторические хроники и родословные, как источники по истории бурят. Улан-Удэ: Изд-во ОАО «Рес. тип.», 2001. $255 \mathrm{c.}$

Эрдэнэболд 2012 - Эрдэнэболд Лхагвасурэн. Традиционные верования ойрат-монголов (конец XIX - начало XX в.) / пер. на рус. яз.: Ганбат Нямдаг, С. Б. Миягашева, Ж. Б. Бадагаров. Улан-Удэ: Изд-во БНЦ СО РАН, 2012. 196 c.

Dugarov D. S. The Khongodor: ethnic origins revisited. In: Zoriktuev B. R. (ed.) Ethnic History of Southern Siberia and Central Asia. Novosibirsk: Nauka. 1993. Pp. 207-235. (In Russ.)

Dyakonov I. M. The 'Cimmerians': ethnic history research methods revisited. In: Asimov M. S. et al. (eds.) Ethnic Problems of the History of Central Asia in the Early Period ( $2^{\text {nd }}$ Millennium BC). Moscow: Nauka, 1981. Pp. 90-100. (In Russ.)

Dyrenkova N. P. Vestiges of the maternal clan among Altaian Turks. Sovetskaya etnografiya. 1937. No. 4. Pp. 18-45. (In Russ.)

Erdenebold Lkhagvasuren. Traditional Beliefs of Oirat Mongols: Late $19^{\text {th }}-$ Early $20^{\text {th }}$ Centuries. Ganbat Nyamdag, S. Miyagasheva, Zh. Badagarov (transl.). Ulan-Ude: Buryat Scientific Center (Siberian Branch of RAS), 2012. 196 p. (In Russ. and Mong.) 
Funk D. A. Teleut Shamanism: Traditional Ethnographic Interpretations and New Research Opportunities. Moscow: Institute of Ethnology and Anthropology (RAS), 1997. 268 p. (In Russ.)

Galdanova G. R. Zakamna Buryats: Historical and Ethnographic Essays, Mid-19 ${ }^{\text {th }}-$ Mid-20 $0^{\text {th }}$ Centuries. Novosibirsk: Nauka. 1992. 172 p. (In Russ.)

Galzut Tubshinima. The Barghut (Barga Mongols): History of Origins. D. Nimaev, L. Badmaeva (foreword, comments); L. Badmaeva, Yu. Badmaeva (translit., transl.). Ulan-Ude: Buryat Scientific Center (Siberian Branch of RAS), 2008. 188 p. (In Russ. and Mong.)

Jamtsarano Ts. Travel Diaries: 1903-1907. V. Lyksokova, Ts. Vanchikova, I. Kulganek (comps.). Ulan-Ude: Respublikanskaya Tipografiya, 2001. 380 p. (In Russ.)

Karunovskaya L. E. Child-related beliefs and rites of the Altaians. In: Museum of Anthropology and Ethnography. Collected Papers. Vol. 6. Leningrad: USSR Academy of Sciences, 1927. Pp. 19-36. (In Russ.)

Khangalov M. N. Collected Works. Vol. 1. UlanUde: Buryat Book Publ., 1958. 551 p. (In Russ.)

Nanzatov B. Z. Ethnogenesis of Western Buryats: $6^{\text {th }}$ to $19^{\text {th }}$ Centuries. Irkutsk: Radian, 2005. 155 p. (In Russ.)

Nanzatov B. Z. Turkic stratum in Buryat ethnonymy: the era of Turkic Khaganates. In: Konovalov P. B. (ed.) Ethnic and Cultural Genesis in the Baikal Region (Middle Ages). Ulan-Ude: Buryat Scientific Center (Siberian Branch of RAS), 2010. Pp. 330-350. (In Russ.)

Novgorodova E. A. Ancient Mongolia: Some Issues of Chronology and Ethnocultural History Revisited. Moscow: Nauka, 1989. 382 p. (In Russ.)

Okladnikov A. P. A deer stone from the Ivolga River Valley. In: Okladnikov A. P. History and Culture of Buryatia. Ulan-Ude: Buryat Book Publ., 1976. Pp. 343-360. (In Russ.)

Okladnikov A. P. Petroglyphs of Lake Baikal Monuments of Ancient Siberian Culture. Novosibirsk: Nauka, 1974. 161 p. (In Russ.)

Polosmak N. V. The Altaian Lady: a fascinating discovery by Russian archaeologists. Rodina. 1999. No. 4. Pp. 34-41. (In Russ.)

Potapov L. P. Revisiting earliest family forms and related religious beliefs: swan gift tradition of the Khakass people. Sovetskaya etnografiya. 1959. No. 2. Pp. 18-30. (In Russ.)
Raevsky D. S. Scytho-Sarmatian mythologies. In: Tokarev S. A. (ed.) Myths of the World. Vol. 2. Moscow: Rossiyskaya Entsiklopediya, 1992. Pp. 445-450. (In Russ.)

Rashid al-Din. Collected Manuscripts. L. Khetagurov (trans1.). Vol. 1. Book 1. Moscow; Leningrad: USSR Academy of Sciences, 1952. 212 p. (In Russ.)

Roerich Yu. N. Nomadic tribes of Tibet. In: Roerich Yu. N. Tibet and Central Asia: Articles, Lectures, Translations. Samara: Agni, 1999. Pp. 88-94. (In Russ.)

Roerich Yu. N. The animal style among the nomads of Northern Tibet. In: Roerich Yu. N. Tibet and Central Asia: Articles, Lectures, Translations. Samara: Agni, 1999. Pp. 29-50. (In Russ.)

Rumyantsev G. N. Origins of the Khori Buryats. Ulan-Ude: Buryat Book Publ., 1962. 265 p. (In Russ.)

Sagalaev A. M. The Life-Giving Bird: Turko-Ugric mythological parallels revisited. In: Gemuev I. N. (ed.) Worldviews of the Finno-Ugric Peoples. Novosibirsk: Nauka, 1990. Pp. 21-34. (In Russ.)

Sevortyan E. V. Etymological Dictionary of Turkic Languages: Common and Intra-Turkic Word Stems Beginning with Vowels. Moscow: Nauka, 1974. 768 p. (In Turk. and Russ.)

Sidorov E. S. Yakut (-Turkic) Lexical Affinities. Yakutsk: Yakutsk State University, 1997. Vol. 1. 146 p. (In Russ.)

The Secret History of the Mongols. S. Kozin (transl.). Ulan-Ude: Buryat Book Publ., 1990. 147 p. (In Russ.)

Tsydendambaev Ts. B. Buryat Chronicles and Genealogical Tables as Sources in Ethnic History. Ulan-Ude: Respublikanskaya Tipografiya, 2001. 255 p. (In Russ.)

Zoriktuev B. R. Ethnic History of Mongols and Buryats: Topical Issues. Moscow: Vostochnaya Literatura, 2011. 278 p. (In Russ.)

Zoriktuev B. R. Nayan-Nava and the ethnogenesis problem of the Buryat tribal community of Khori. Nauchnyi dialog. 2020. No. 5. Pp. 393423. (In Russ.) DOI: 10.24224/2227-12952020-5-393-423

Zoriktuev B. R. On the little-known aspects of the ethnic history of the Khori. Issues of SocialEconomic Development of Siberia. 2018. No. 4(34). Pp. 127-132. (In Russ.)

Zoriktuev B. R. To the history of the Khori tribal group. Bulletin of Kalmyk University. 2019. No. 3 (43). Pp. 13-19. (In Russ.) 